\title{
Does Sars-Cov-2 threaten our dreams? Effect of quarantine on sleep quality and body mass index
}

\author{
Luigi Barrea ${ }^{1,2^{*}}$ (D) , Gabriella Pugliese ${ }^{1,2}$, Lydia Framondi ${ }^{1}$, Rossana Di Matteo ${ }^{1}$, Daniela Laudisio ${ }^{1,2}$, \\ Silvia Savastano ${ }^{1,2}$, Annamaria Colao ${ }^{1,2,3}$ and Giovanna Muscogiuri, ${ }^{1,2}$
}

\begin{abstract}
Background: COVID 19-related quarantine led to a sudden and radical lifestyle changes, in particular in eating habits. Objectives of the study were to investigate the effect of quarantine on sleep quality (SQ) and body mass index (BMI), and if change in SQ was related to working modalities.

Materials: We enrolled 121 adults (age $44.9 \pm 13.3$ years and 35.5\% males). Anthropometric parameters, working modalities and physical activity were studied. Sleep quality was evaluated by the Pittsburgh Sleep Quality Index (PSQI) questionnaire. At baseline, the enrolled subjects were assessed in outpatient clinic and after 40 days of quarantine/ lockdown by phone interview.

Results: Overall, $49.6 \%$ of the subjects were good sleepers (PSQ $<5)$ at the baseline and significantly decreased after quarantine $(p<0.001)$. In detail, sleep onset latency $(p<0.001)$, sleep efficiency $(p=0.03)$, sleep disturbances $(p<0.001)$, and daytime dysfunction $(p<0.001)$ significantly worsened. There was also a significant increase in BMI values in normal weight $(p=0.023)$, in subjects grade I $(p=0.027)$ and II obesity $(p=0.020)$. In all cohort, physical activity was significantly decreased $(p=0.004)$. However, analyzing the data according gender difference, males significantly decreased physical activity as well as females in which there was only a trend without reaching statistical significance ( $53.5 \%$ vs $25.6 \% ; p=0.015$ and $50.0 \%$ vs $35.9 \%, p=0.106$; in males and females, respectively). In addition, smart working activity resulted in a significant worsening of $\mathrm{SQ}$, particularly in males $(p<0.001)$.
\end{abstract}

Conclusions: Quarantine was associated to a worsening of $\mathrm{SQ}$, particularly in males doing smart working, and to an increase in BMI values.

Keywords: CoVID-19, Sars-Cov-2, Obesity, Quarantine, Sleep disturbance, Sleep quality, Smart-working, Nutritionist

\section{Background}

Recently the whole world experienced the enormous stress of the pandemic of severe acute respiratory syndrome coronavirus 2 (SARS-CoV-2) that began in Wuhan, Hubei, China in late 2019 and it has been

\footnotetext{
*Correspondence: luigi.barrea@unina.it

${ }^{1}$ Dipartimento di Medicina Clinica e Chirurgia, Unit of Endocrinology,

Federico II University Medical School of Naples, Via Sergio Pansini 5,

80131 Naples, Italy

Full list of author information is available at the end of the article
}

renamed CoVID-19 by the World Health Organization on February 2020 [1]. In order to reduce the spread of the virus and to reduce the impact of a huge number of infected subjects on medical resources, at the beginning of March 2020 Italy went into emergency quarantine, with stringent containment measures on the entire national territory [2]. These containment measures enacted through the \#iorestoacasa decree [2] that leads to a sudden and radical lifestyle changes, in particular in eating habits. Quarantine leads to staying at home with smart-working and the reduction of the outdoors

(c) The Author(s) 2020. This article is licensed under a Creative Commons Attribution 4.0 International License, which permits use, sharing, adaptation, distribution and reproduction in any medium or format, as long as you give appropriate credit to the original author(s) and the source, provide a link to the Creative Commons licence, and indicate if changes were made. The images or other third party material in this article are included in the article's Creative Commons licence, unless indicated otherwise in a credit line to the material. If material is not included in the article's Creative Commons licence and your intended use is not permitted by statutory regulation or exceeds the permitted use, you will need to obtain permission directly from the copyright holder. To view a copy of this licence, visit http://creativeco mmons.org/licenses/by/4.0/. The Creative Commons Public Domain Dedication waiver (http://creativecommons.org/publicdomain/ zero/1.0/) applies to the data made available in this article, unless otherwise stated in a credit line to the data. 
physical activity or in the gym. Of interest, quarantine could be also associated with an unhealthy diet, poor in fresh foods as fruit and vegetables and rich in processed food due to the limitation on daily shopping. It is known that an unhealthy diet is associated with obesity and sleep disturbance [3]. In particular poor diet quality characterized by high fat and low fiber intake has been reported to be associated to sleep disturbance $[4,5]$. In addition to fat, carbohydrates-rich meal in the evening has been reported to results in an increase of core body temperature ad heart rate and in a reduction of nocturnal secretion of melatonin within the $8 \mathrm{~h}$ after the end of the meal consumption in healthy normal weight subjects [6, 7]. Most of the time carbohydrates, in particular sugars, are identified as 'comfort foods' due to their property of increasing serotonin production that in turn has a positive effect on mood [8]. In a sense, carbohydrate-rich foods can be a way of self-medicating anti stress and the positive effect of carbohydrates on mood is proportional to the glycemic index of foods. For this reason they could represent the best allies to fight quarantine-related low mood thus giving rise to the so called 'emotional eating' [9-11]. This condition is further exacerbated by the disruption in everyday life that along with continuously hearing or reading about the pandemic, could have led to a stressful condition pushing people toward overeating and increasing the risk of developing obesity.

This latter per se is currently one of the most important risk factors of sleep disturbance [3, 12, 13]. Although obesity-related sleep disturbance are mostly due to obstructive sleep apnea (OSA) [14], that is characterized by recurrent narrowing and closure of the upper airway, leading to intermittent oxyhemoglobin desaturation, sleep fragmentation and daytime sleepiness [15], both sleep quality (SQ), and sleep duration have been found to be blunted in subjects with obesity without OSA [16]. Indeed Resta et al. carried out a study in subjects with obesity and without OSA or diseases that are known to be associated with sleep disturbance such as endocrine, psychiatric, and neuromuscular diseases [16]. They found a high prevalence of sleep disturbance such as choking, awakening and unrefreshing sleep, in subjects with obesity than in normal-weight subjects [16]. In addition to OSA, sleep disturbance in obesity could be caused by other obesity-related diseases, such as functional gastrointestinal disorders, including irritable bowel syndrome and functional dyspepsia, nicturia, asthma and osteoarticular pain $[12,17]$.

In both genders waist circumference has been reported to have a tight association with sleep disturbance [18]. This is because visceral adipose tissue is the main source of pro-inflammatory cytokines, such as interleukin (IL)1 , IL-6 and tumor necrosis factor (TNF)- $\alpha$ that, beyond chronic low-grade inflammation [19, 20], could have a role in sleep regulation such that they are called 'sleepregulatory substances' [21,22]. Quarantine was also associated with a change of working modalities in most of the people. Indeed they switched to smart-working that could be associated not only to a greater energy intake but also to a decrease secretion of melatonin due to the evening screen time, thus contributing to sabotage sleep [23].

In light of what has been said so far, the primary objective of this study was to investigate the effect of quarantine on sleep quality and on body mass index in Italian adults. The second objective of the study was to investigate if change in sleep quality after quarantine was related to working modalities.

\section{Materials and methods Design and setting}

This was a retrospective study carried out at the Department of Clinical Medicine and Surgery, Unit of Endocrinology, University Federico II, Naples (Italy), from January 2020 to 30 April 2020 in accordance with the Code of Ethics of the World Medical Association (Declaration of Helsinki) for experiments involving humans. The purpose of the protocol was explained to all the study participants, and their consent was obtained.

\section{Population study}

All participants started quarantine on March 12th 2020 and the effects on sleep quality were assessed after 40 days. In order to increase the homogeneity of the subject samples, we included only adults of both gender with the following criteria of exclusion evaluated at baseline:

- Clinical conditions such as schizophrenia, depression, chronic or recurrent respiratory conditions, active cancer or neurological disorders;

- Chronic metabolic and cardiovascular diseases including type 2 diabetes mellitus, hypertension, dyslipidemia that could interfere with sleep disturbance;

- Smoking subjects;

- Sleep disorders such as obstructive sleep apneahypopnea syndrome;

- Excessive alcohol use (>4 cups/day) or excessive caffeine use (>500 mg/day);

- Pregnancy or lactation.

One-hundred twenty-one subjects (43 males and 78 females) aged 18-65 years were found to be eligible.

\section{Power size justification}

The power sample was calculated by the differences of means \pm standard deviations (SD) of the Pittsburgh 
Sleep Quality Index (PSQI) global score at pre and post quarantine $(6.37 \pm 3.96$ vs $8.64 \pm 3.73, p<0.001)$. Considering a type I (alpha) error of 0.05 (95\%), and a type II (beta) of 0.05 , and the calculated power size was $95 \%$, the minimum number of cases required for a statistical power of $95 \%$ was of 40 cases. The calculation of sample size and power were performed while using Sample Size Calculator Clinical Calc (https://clincalc.com/stats /samplesize.aspx), as previously reported in other studies [24-26].

\section{Data collection and measurements}

Data were collected at baseline in our obesity outpatient clinic by face-to-face assessment and after 40 days of quarantine by the telephone interview (self-reported). The phone calls are based on interviewing for specific related questions on anthropometric data, physical activity data, sleep quality, current medications of sleep disturbance and working modalities. For self-measurement of anthropometric data, instructions were given to the participants by a qualified nutritionist.

\section{Anthropometric measurements}

At baseline, measurements were performed between 8 am and $10 \mathrm{am}$, after an overnight fast. A single nutritionist measured weight and height parameters performed following standard criteria by the same nutritionist according to the International Society for the Advancement of Kinanthropometry (ISAK 2006). The participants were recommended to dress light clothes and to remove shoes during the assessment, as previously reported [27-29]. Body mass index (BMI) [weight (kg) divided by height squared $\left.\left(\mathrm{m}^{2}\right), \mathrm{kg} / \mathrm{m}^{2}\right]$ was calculated after measuring weight and height. A wall-mounted stadiometer (Seca 711; Seca, Hamburg, Germany) was used to measure height while a calibrated balance beam scale (Seca 711; Seca, Hamburg, Germany) was used to assess weight. The degree of obesity was established according to World Health Organization's criteria: BMI: $18.5-24.9 \mathrm{~kg} / \mathrm{m}^{2}$, normal-weight; $25.0-29.9 \mathrm{~kg} / \mathrm{m}^{2}$, over-weight; BMI: $30.0-34.9 \mathrm{~kg} / \mathrm{m}^{2}$, grade I obesity; BMI: $35.0-39.9 \mathrm{~kg} / \mathrm{m}^{2}$, grade II obesity; BMI $\geq 40.0 \mathrm{~kg} / \mathrm{m}^{2}$, grade III obesity [30].

After 40 days of quarantine, weight and height were collected by telephone interview. Participants were asked to report their body weight with the question: what is your current body weight? (in $\mathrm{kg}$ ). In particular, selfreported body weight was collected asking the subjects to weight in the morning before breakfast under wearing light clothes (round to $0.5 \mathrm{~kg}$ ). Self-reported height was obtained asking the subject: "What is your height?" in $\mathrm{cm}$, as also previously reported by Dekkers et al. [31].

\section{Assessment of sleep quality, physical activity, and working modalities}

Sleep quality, physical activity, and working modalities were evaluated during the telephone interview (self-reported). Sleep quality was evaluated using the Pittsburgh Index questionnaire that include seven components: subjective sleep quality, sleep latency, sleep duration, habitual sleep efficiency, sleep disturbances, sleep medication use, and daytime dysfunction [32]. Each of these seven items are equally weighted based on 0 to 3 points, whereby three reflects the negative extreme on the Likert Scale. The global PSQI score ranging from zero to 21 points, with higher scores indicating poorer sleep quality. In according to Buysse DJ et al. poor sleep quality was defined as a PSQI score $\geq 5$, while good sleep quality was defined as PSQI score $<5$ [32]. The participants habitually engaged in at least $30 \mathrm{~min} /$ day of aerobic exercise (YES/NO) was defined as physically active, as we have already fully reported in previous studies [33, 34]. Working modalities have been evaluated as: smart working (YES/NO).

\section{Statistical analysis}

Results are expressed as mean \pm SD and categorical variables are expressed as a percentage. Differences between pre and post quarantine were analyzed by Student's paired $t$ test or by Student's impaired $t$ test for the differences between males and females. The Chi square $\left(x^{2}\right)$ test was used to determine the significance of differences in frequency distribution of BMI categories, PSQI categories and physical activity. Differences in $\Delta \%$ variation of PSQI score pre and post-quarantine in the population study across BMI categories (normal weight, overweight, grade I obesity, grade II obesity and grade III obesity) were analyzed by ANOVA test, with the Bonferroni test as post hoc test. An Alfa $\alpha$ level of 0.05 (type 1 error) and a $\beta$ level of 0.2 (type II error) were used as the cut-off values for statistical significance. Variables with a variance inflation factor $>10$ were excluded in order to avoid multicollinearity. Values $\leq 5 \%$ were considered statistically significant. Data were collected and analyzed using the MedCalc ${ }^{\circledR}$ package (Version 12.3.0 1993-2012 -Mariakerke, Belgium).

\section{Results}

All participants started quarantine on March 12th 2020 and were interviewed after 40 days of quarantine by the same operator. Forty-three (35.5\%) participants were males, aged $44.9 \pm 13.3$ years. The characteristics of 121 participants, including anthropometric characteristics and physical activity pre and post quarantine were summarized in Table 1. BMI significantly increased post 
Table 1 Anthropometric characteristics and physical activity of the study population pre and post-quarantine

\begin{tabular}{|c|c|c|c|}
\hline Parameters & $\begin{array}{l}\text { Participants } \\
\text { pre- } \\
\text { quarantine } \\
\text { mean } \pm \text { SD } \\
\text { or number } \\
(\%) \\
n=121\end{array}$ & $\begin{array}{l}\text { Participants } \\
\text { post- } \\
\text { quarantine } \\
\text { mean } \pm S D \\
\text { or number } \\
(\%) \\
n=121\end{array}$ & ${ }^{*} p$ value \\
\hline Weight (kg) & $88.1 \pm 18.9$ & $89.9 \pm 19.2$ & $<0.001$ \\
\hline Height (m) & $1.64 \pm 0.1$ & $1.64 \pm 0.1$ & 0.516 \\
\hline $\mathrm{BMI}\left(\mathrm{kg} / \mathrm{m}^{2}\right)$ & $32.6 \pm 6.0$ & $33.3 \pm 6.2$ & $<0.001$ \\
\hline Males & $33.5 \pm 6.1$ & $33.9 \pm 5.9$ & 0.045 \\
\hline Females & $32.1 \pm 5.9$ & $32.9 \pm 6.3$ & 0.001 \\
\hline $\begin{array}{l}\text { Normal-weight } \\
(n, \%)\end{array}$ & $11,9.1 \%$ & $7,5.8 \%$ & $x^{2}=0.54, p=0.462$ \\
\hline Overweight (n, \%) & $31,25.6 \%$ & $30,24.8 \%$ & $x^{2}=0.01, p=1.000$ \\
\hline $\begin{array}{l}\text { Grade I obesity } \\
\quad(n, \%)\end{array}$ & $41,33.9 \%$ & $40,33.1 \%$ & $x^{2}=0.01, p=1.000$ \\
\hline $\begin{array}{l}\text { Grade Il obesity } \\
(n, \%)\end{array}$ & $25,20.7 \%$ & $25,20.7 \%$ & $x^{2}=0.02, p=0.874$ \\
\hline $\begin{array}{l}\text { Grade III obesity } \\
\quad(n, \%)\end{array}$ & $13,10.7 \%$ & $19,15.7 \%$ & $x^{2}=0.90, p=0.342$ \\
\hline $\begin{array}{l}\text { Physical activity } \\
\text { (yes) }\end{array}$ & $62,51.2 \%$ & $39,32.2 \%$ & $x^{2}=8.23, p=0.004$ \\
\hline
\end{tabular}

${ }^{*} A p$ value in italic type denotes a significant difference $(p<0.05)$. SD, standard deviation; BMI, Body mass index

Table 2 Single items of PSQI, PSQI global score and PSQI categories of the study population pre and postquarantine

\begin{tabular}{llll}
\hline $\begin{array}{l}\text { Parameters of PSQI } \\
\text { questionnarie }\end{array}$ & $\begin{array}{l}\text { Participants } \\
\text { pre-quarantine } \\
\text { mean } \pm \text { SD } \\
\mathbf{n = 1 2 1}\end{array}$ & $\begin{array}{l}\text { Participants } \\
\text { post-quarantine } \\
\text { mean } \pm \text { SD } \\
\mathbf{n = 1 2 1}\end{array}$ & * $\boldsymbol{p}$-value \\
\hline Sleep quality & $1.05 \pm 0.85$ & $1.69 \pm 0.83$ & $<0.001$ \\
Sleep onset latency & $1.03 \pm 0.98$ & $1.61 \pm 1.09$ & $<0.001$ \\
Sleep duration & $1.07 \pm 1.04$ & $1.06 \pm 0.97$ & 0.902 \\
Sleep efficiency & $0.61 \pm 0.98$ & $0.88 \pm 1.07$ & 0.003 \\
Sleep disturbance & $1.26 \pm 0.68$ & $1.71 \pm 0.77$ & $<0.001$ \\
Hypnotic drugs & $0.31 \pm 0.81$ & $0.22 \pm 0.69$ & 0.068 \\
Daytime dysfunction & $1.04 \pm 0.98$ & $1.46 \pm 0.96$ & $<0.001$ \\
PSQI global score & $6.37 \pm 3.96$ & $8.64 \pm 3.73$ & $<0.001$ \\
PSQI categories & & & $x^{2}=23.76$ \\
PSQI $<5$ & $60,49.6 \%$ & $23,19.0 \%$ & $p<0.001$ \\
PSQI $\geq 5$ & $61,50.4 \%$ & $98,81.0 \%$ & \\
\hline
\end{tabular}

${ }^{*}$ A $p$ value in italic type denotes a significant difference $(p<0.05)$

quarantine $(p<0.001)$ in all cohort and in both genders. Subjects reported to reduce physical activity during the quarantine $(p=0.004)$.

Table 2 showed the differences of the single items of PSQI questionnaire, PSQI global score and PSQI categories of the studied population pre and post quarantine. Sleep quality significantly worsened during quarantine as demonstrated by the increase of PSQI score $(p<0.001)$, sleep onset latency score $(p<0.001)$, sleep efficiency score $(p=0.003)$, sleep disturbance score $(p<0.001)$, and daytime dysfunction score $(p<0.001)$. Thirty\% of participants worsened their sleep quality $(p<0.001)$.

The BMI and PSQI global score pre and post-quarantine in the population study across BMI categories were shown in Fig. 1. As reported, stratifying the sample population according to the BMI categories pre and post-quarantine, BMI increased in post-quarantine in normal weight (11 subjects, $21.84 \pm 1.98 \mathrm{~kg} /$ $\mathrm{m}^{2}$ vs $23.22 \pm 2.42 \mathrm{~kg} / \mathrm{m}^{2}$ ), grade I obesity (41 subjects, $32.58 \pm 1.38 \mathrm{~kg} / \mathrm{m}^{2}$ vs $33.35 \pm 2.49 \mathrm{~kg} / \mathrm{m}^{2}$ ), and grade II obesity (25 subjects, $37.23 \pm 1.21 \mathrm{~kg} / \mathrm{m}^{2}$ vs $38.41 \pm 2.94 \mathrm{~kg} / \mathrm{m}^{2}$ ); while no differences were observed in overweight (31 subjects, $28.02 \pm 1.34 \mathrm{~kg} / \mathrm{m}^{2}$ vs $28.30 \pm 1.49 \mathrm{~kg} / \mathrm{m}^{2}$ ) and grade III obesity (13 subjects, $43.65 \pm 2.77 \mathrm{~kg} / \mathrm{m}^{2}$ vs $43.59 \pm 2.59 \mathrm{~kg} / \mathrm{m}^{2}$ ). Accordingly in post-quarantine PSQI global score was increased in normal weight (11 subjects, $5.09 \pm 3.59$ vs $7.91 \pm 3.08$ score), over weight ( 31 subjects, $5.22 \pm 3.53$ vs $8.03 \pm 3.37$ score), grade I obesity ( 41 subjects, $6.27 \pm 3.66$ vs $9.00 \pm 3.59$ score), and grade II obesity (25 subjects, $6.92 \pm 3.76$ vs $8.44 \pm 4.02$ score), but no difference has been shown in grade III obesity (13 subjects, $9.46 \pm 5.15$ vs $10.00 \pm 4.86$ score); Fig. 1.

Figure 2 reported the \% of poor sleepers (PSQI $\geq 5$ ) pre and post-quarantine across BMI categories. In detail, stratifying the sample population according to BMI categories, the \% of poor sleepers significantly increases in normal weight $(36.4 \%$ vs $72.7 \%)$, over weight $(29 \%$ vs $80.6 \%$ ) and grade I obesity $(53.7 \%$ vs $85.4 \%)$; on the contrary, no difference was observed in grade II obesity $(68.0 \%$ vs $76.0 \%)$ and grade III obesity $(69.2 \%$ vs $84.6 \%)$; Fig. 2.

The $\Delta \%$ variation of PSQI score pre and post-quarantine in the population study across BMI categories were shown in Fig. 3. As showed, stratifying the sample population across the BMI categories the $\Delta \%$ variation of PSQI score decreases with increasing BMI categories. In particular, normal weight had the highest $\Delta \%$ variation of PSQI score $(135.00 \pm 109.16)$ compared to overweight $(95.16 \pm 146.35)$, grade I obesity $(94.05 \pm 85.14)$, grade II obesity $(49.43 \pm 102.71)$, and grade II obesity (19.29 \pm 64.66$)$; Fig. 3.

The pre and post quarantine gender difference in the single items of PSQI questionnaire, PSQI global score and PSQI categories of the study population, were reported in Table 3. In both gender, there was a worsening of sleep quality. Of interest, although at baseline 


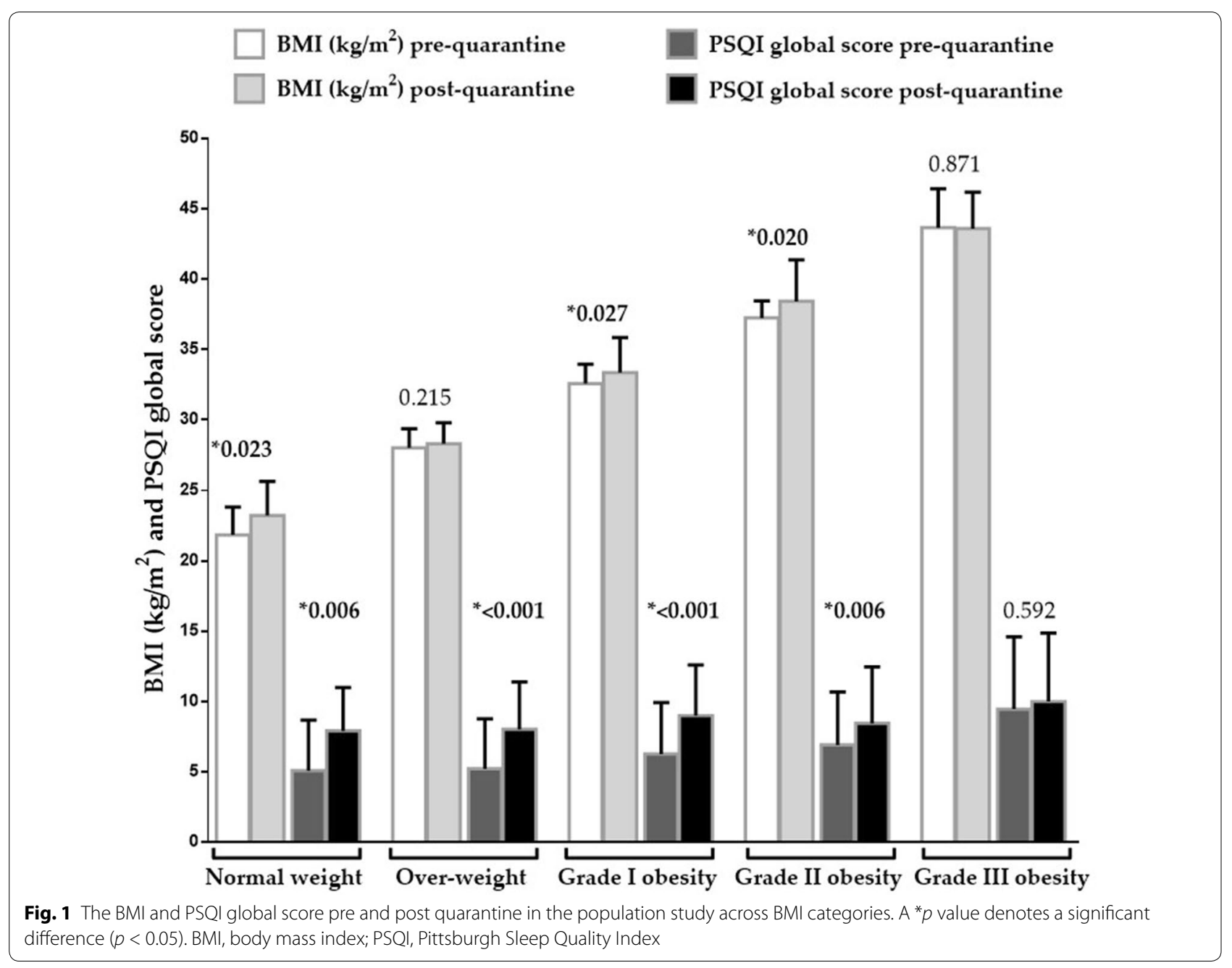

the percentage of good sleepers were higher in males than females $(60.5 \%$ vs $43.6 \%$ of PSQI $<5)$, a higher percentage of males became poor sleepers compared to females $(44.2 \%$ vs $23.1 \%$ of PSQI $\geq 5)$. In addition, a higher percentage of males decreased physical activity levels $(-27.9 \%, p=0.015)$, while no significant differences were shown in females $(p=0.106)$. However, a gender difference in terms of changes of physical activity habits was reported post quarantine $(p=0.016)$ (Table 3).

The differences in $\Delta \%$ variation of PSQI score according to working modalities in all participants divided by gender, were summarized in Table 4 . In both males $(p<0.001)$ and females $(p=0.002)$ there was a worsening of sleep quality that was significantly higher in subjects performing smart working compared to subjects not performing smart working. In addition, males performing smart working had a significantly higher worsening of sleep quality than females performing smart working $(p<0.001)$.

\section{Discussion}

To the best of our knowledge, this study was the first to investigate the effect of quarantine/lockdown due to the COVID-19 pandemic on sleep quality in Italian population subjects. The main results of our study are the worsening sleep quality, the increase in BMI and the reduction of physical activity after quarantine. Sleep quality was mostly worsened in subjects performing smart working compared to subjects not performing smart working in both genders. Males performing smart working had a significantly worse sleep quality than their female counterparts working in the same modality.

\section{Sleep quality}

Study findings revealed that quarantine resulted in a worsening of sleep quality in normal weight and 


\section{$a=$ pre-quarantine; $b=$ post-quarantine}

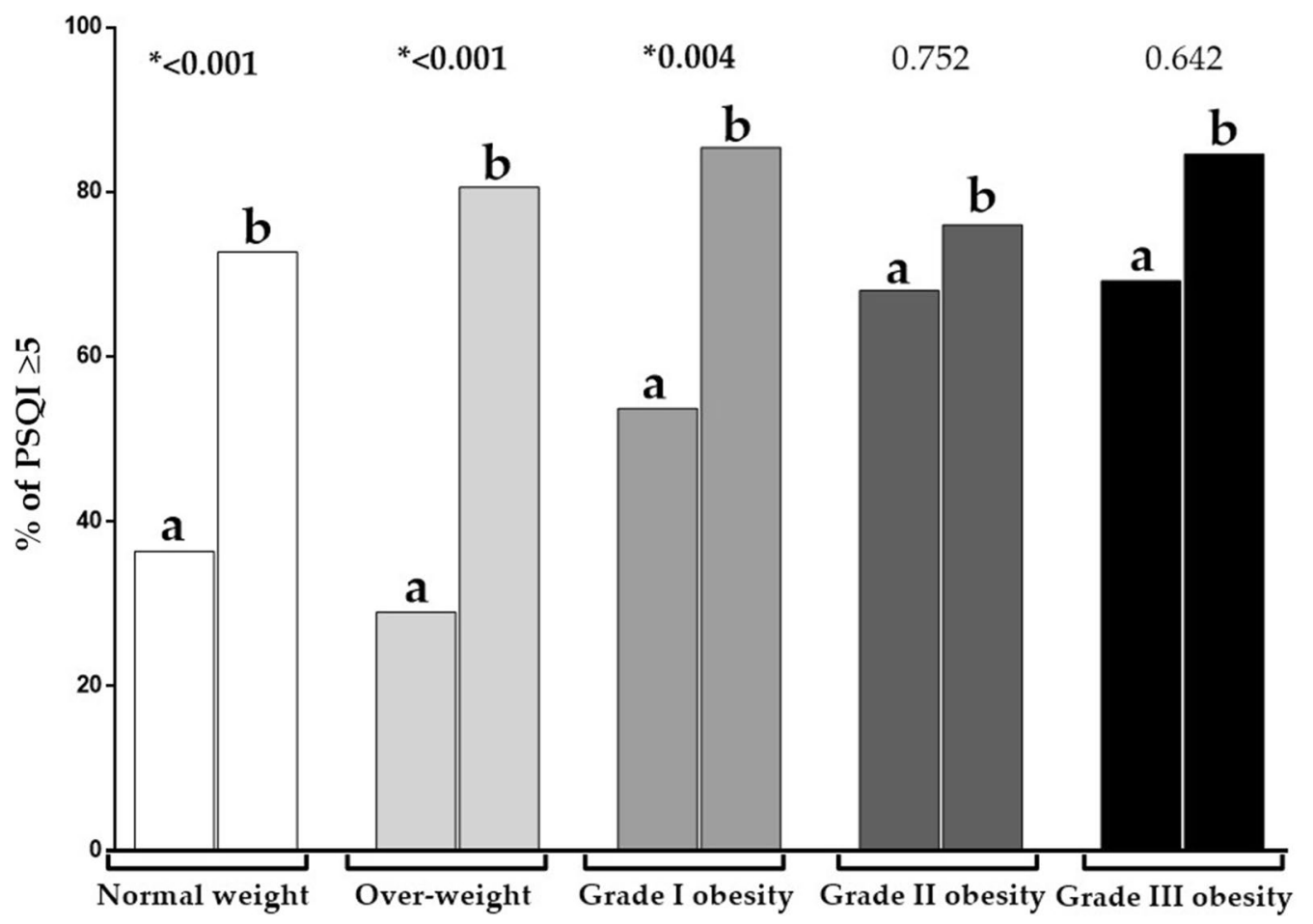

Fig. 2 Percentage of PSQI $\geq 5$ pre and post-quarantine across BMI categories. A * $p$ value denotes a significant difference $(p<0.05)$. PSQI, Pittsburgh Sleep Quality Index

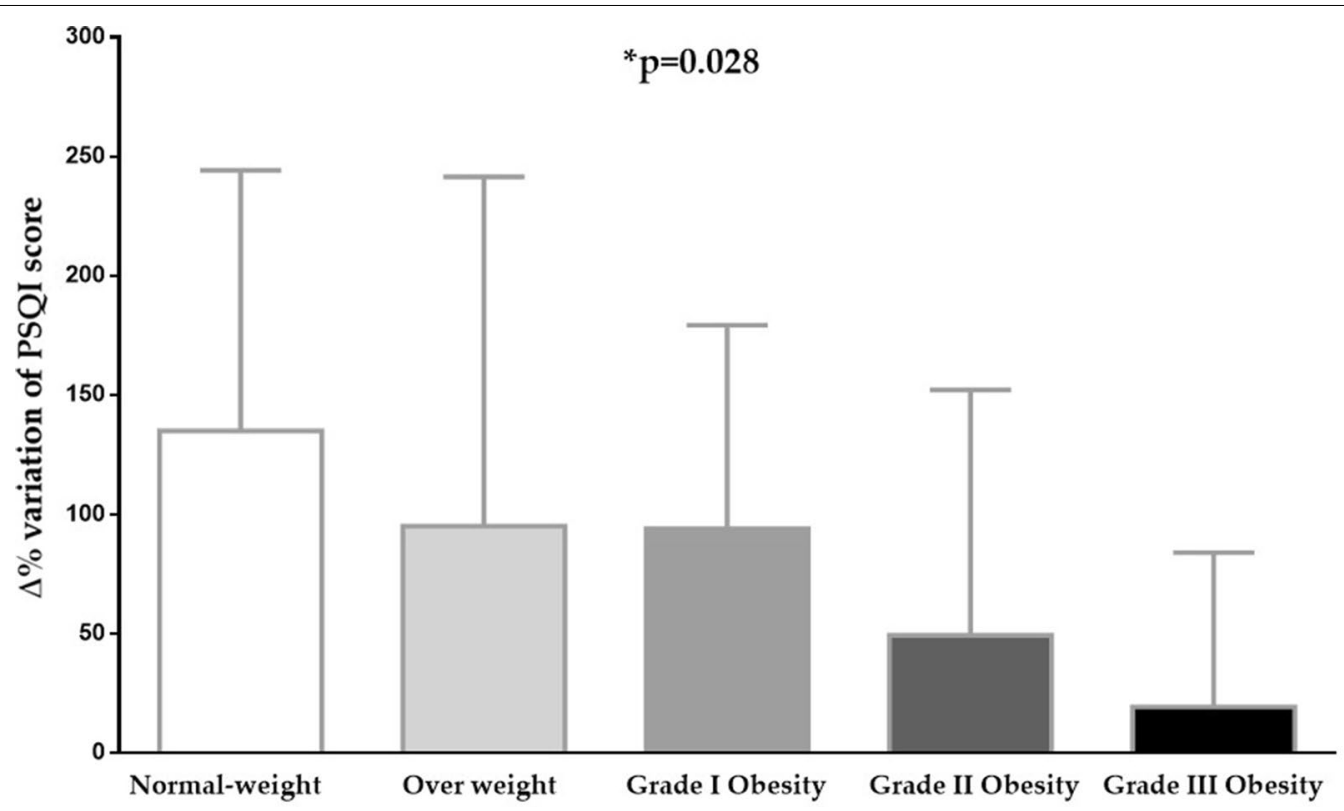

Fig. 3 Delta \% variation of PSQI score pre and post-quarantine in the population study across BMI categories. A * $p$ value denotes a significant difference $(p<0.05)$. PSQI, Pittsburgh Sleep Quality Index 
Table 3 Single items of PSQI, PSQI global score and PSQI categories of the study population pre and post quarantine, according to gender

\begin{tabular}{|c|c|c|c|c|c|c|c|c|c|}
\hline \multirow[t]{2}{*}{ Parameters } & \multicolumn{4}{|c|}{$\begin{array}{l}\text { Male participants } \\
\text { mean } \pm S D \\
n=43\end{array}$} & \multicolumn{4}{|c|}{$\begin{array}{l}\text { Female participants } \\
\text { mean } \pm \text { SD } \\
n=78\end{array}$} & \multirow[b]{2}{*}{${ }^{* *} p$-value $\Delta \%$} \\
\hline & $\begin{array}{l}\text { Pre } \\
\text { quarantine }\end{array}$ & $\begin{array}{l}\text { Post } \\
\text { quarantine }\end{array}$ & $\Delta \%$ & ${ }^{*} p$-value & $\begin{array}{l}\text { Pre } \\
\text { quarantine }\end{array}$ & $\begin{array}{l}\text { Post } \\
\text { quarantine }\end{array}$ & $\Delta \%$ & ${ }^{*} p$-value & \\
\hline Sleep quality & $0.91 \pm 0.94$ & $1.49 \pm 0.73$ & $48.83 \pm 58.99$ & $<0.001$ & $1.13 \pm 0.77$ & $1.81 \pm 0.85$ & $47.22 \pm 72.49$ & $<0.001$ & 0.901 \\
\hline $\begin{array}{l}\text { Sleep onset } \\
\text { latency }\end{array}$ & $0.98 \pm 1.06$ & $1.58 \pm 1.00$ & $54.45 \pm 76.29$ & $<0.001$ & $1.06 \pm 0.94$ & $1.63 \pm 1.14$ & $48.50 \pm 90.10$ & $<0.001$ & 0.701 \\
\hline $\begin{array}{l}\text { Sleep dura- } \\
\text { tion }\end{array}$ & $1.11 \pm 1.16$ & $1.02 \pm 1.10$ & $2.33 \pm 33.10$ & 0.400 & $1.04 \pm 0.97$ & $1.08 \pm 0.89$ & $11.75 \pm 49.50$ & 0.650 & 0.214 \\
\hline $\begin{array}{l}\text { Sleep effi- } \\
\text { ciency }\end{array}$ & $0.56 \pm 0.96$ & $0.72 \pm 0.91$ & $19.96 \pm 43.54$ & 0.109 & $0.64 \pm 1.00$ & $0.97 \pm 1.14$ & $41.24 \pm 94.30$ & 0.011 & 0.093 \\
\hline $\begin{array}{l}\text { Sleep distur- } \\
\text { bance }\end{array}$ & $1.11 \pm 0.66$ & $1.77 \pm 0.81$ & $40.31 \pm 56.84$ & $<0.001$ & $1.35 \pm 0.68$ & $1.68 \pm 0.75$ & $20.94 \pm 43.16$ & 0.002 & 0.037 \\
\hline $\begin{array}{l}\text { Hypnotic } \\
\text { drugs }\end{array}$ & $0.21 \pm 0.63$ & $0.21 \pm 0.63$ & $0.00 \pm 0.00$ & 0.999 & $0.36 \pm 0.89$ & $0.23 \pm 0.72$ & $-2.88 \pm 20.13$ & 0.068 & 0.350 \\
\hline $\begin{array}{l}\text { Daytime dys- } \\
\text { function }\end{array}$ & $0.79 \pm 0.89$ & $1.51 \pm 0.86$ & $60.27 \pm 67.50$ & $<0.001$ & $1.18 \pm 1.01$ & $1.44 \pm 1.01$ & $35.89 \pm 82.98$ & 0.084 & 0.083 \\
\hline $\begin{array}{l}\text { PSQI global } \\
\text { score }\end{array}$ & $5.67 \pm 4.31$ & $8.30 \pm 3.63$ & $98.85 \pm 103.60$ & $<0.001$ & $6.76 \pm 3.73$ & $8.83 \pm 3.80$ & $62.99 \pm 110.75$ & $<0.001$ & 0.079 \\
\hline \multicolumn{10}{|c|}{ PSQI categories } \\
\hline$P S Q \mid<5$ & $26,60.5 \%$ & $7,16.3 \%$ & \multirow{2}{*}{\multicolumn{2}{|c|}{$x^{2}=15.93 p=0.001$}} & $34,43.6 \%$ & $16,20.5 \%$ & \multirow{2}{*}{\multicolumn{2}{|c|}{$x^{2}=8.51 p=0.004$}} & $x^{2}=28.82$ \\
\hline $\mathrm{PSQI} \geq 5$ & $17,39.5 \%$ & $36,83.7 \%$ & & & $44,56.4 \%$ & $62,79.5 \%$ & & & .001 \\
\hline \multicolumn{10}{|c|}{ Physical activity } \\
\hline Yes & $23,53.5 \%$ & $11,25.6 \%$ & \multirow{2}{*}{\multicolumn{2}{|c|}{$x^{2}=5.88 p=0.015$}} & $39,50.0 \%$ & $28,35.9 \%$ & \multirow{2}{*}{\multicolumn{2}{|c|}{$x^{2}=2.62 p=0.106$}} & $x^{2}=10.34$ \\
\hline No & $20,46.5 \%$ & $32,74.4 \%$ & & & $39,50.0 \%$ & $50,64.1 \%$ & & & \\
\hline
\end{tabular}

${ }^{*} \mathrm{~A} p$ value in italic type denotes a significant difference $(p<0.05)$ within the group between pre and post quarantine. ${ }^{* *} \mathrm{~A} p$ value in italic type denotes a significant difference $(p<0.05)$ of $\Delta \%$ of variation between males and females

Table 4 Differences in $\triangle$ PSQI score according to working modalities in all participants divided by gender

\begin{tabular}{lllllll}
\hline Parameters & $\begin{array}{l}\text { All participants } \\
\mathbf{n = 1 2 1}\end{array}$ & $\mathbf{n}$ & Male participants $\mathbf{n = 4 3}$ & $\mathbf{n}$ & $\begin{array}{l}\text { Female participants } \\
\mathbf{n}=\mathbf{7 8}\end{array}$ & ${ }^{* *} \boldsymbol{p}$-value \\
\hline Smart working & & & & & \\
Yes & $39,32.2 \%$ & 16 & $151.41 \pm 94.33$ & 23 & $87.29 \pm 115.52$ & 0.001 \\
No & $82,67.8 \%$ & 27 & $10.17 \pm 35.61$ & 55 & $4.92 \pm 71.96$ \\
$p$-value & & & ${ }^{*} p<0.001$ & & ${ }^{*} p=0.002$ \\
\hline
\end{tabular}

${ }^{*} \mathrm{~A} p$ value in italic type denotes a significant difference $(p<0.05)$ in $\Delta \%$ variation of PSQI in smart working mode (yes vs no) in males and females. ${ }^{* *} \mathrm{~A}$ value in italic type denotes a significant difference $(p<0.05)$ of $\Delta \%$ variation of PSQI between males and females

overweight subjects and in subjects with grade I and II obesity. In particular, there was an increase in sleep onset latency and sleep disturbance in both males and females. There was a significant worsening of sleep efficiency in females while there was a significant worsening of daytime dysfunction in males. There was an increase in BMI in normal weight and in subjects with grade I and II obesity after 40 days of quarantine. In addition, physical activity significantly decreased in all cohort of subjects. However, females had a trend toward the decrease of physical activity while males significantly decreased physical activity. As well known, on March 12th 2020 Italian people experienced locked down in order to reduce the widespread of the pandemic of coronavirus. As consequence, quarantine was associated to the interruption of work routine and these results in economic issues due to economic activity stalls and job losses mount. This generates worries about income, savings, and making ends meet. As a consequence of the lockdown, trips were canceled, and people were isolated from friends and family. Therefore, the isolation at home could generate the depression or exacerbate it in people that 
were already affected. Along with these situations, continuously hearing or reading about the pandemic without a break contributes to the onset of stress. As well known, stress is an adaptive response of the organism to real or perceived stressors. The main components of the stress system are the corticotropin-releasing hormone and locus coeruleus-norepinephrine/autonomic systems that are connected to peripheral effectors such as the hypothalamic-pituitary-adrenal axis, and the limbs of the autonomic system [35]. It has been reported that hypercortisolism can lead to fragmentation of sleep, decreased slow-wave sleep, and shortened sleep time. To complicate matters, sleep disturbances can in turn further worsen hypercortisolism and thereby worsening the cycle [36]. Interestingly the worsening of sleep quality was more evident in subjects with normal weight and in subjects with grade I and II obesity. No further worsening was noticed in subjects with obesity grade III. This could be because subjects with obesity III grade had already a poor sleep quality at the baseline and there was not further worsening margin. As well known, the degree of obesity is directly correlated with sleep quality [12]. Subjects with normal weight and obesity I and II grade experienced an increase of their BMI. This could be explained because they reduced physical activity. Indeed, the excess of adipose tissue narrows breath airways but it is also involved in the releases of cytokines [37]. In particular IL-1, IL-6 and TNF- $\alpha$ are not only pro-inflammatory cytokines but also a 'sleep-regulatory substances' $[21,38]$. TNF- $\alpha$ and IL-1b, whose secretion follows a circadian rhythm, with the highest TNF- $\alpha$ and IL- 6 secretion during the night (between 01:00 and 02:00 h), are involved in the physiological regulation of sleep in both animals and humans [39], playing an important role in the slow-wave sleep [40]. Interestingly males reported a decrease in physical activity. Accordingly, it has been reported that during quarantine outdoor activities and social activities are prohibited by the governments and this could result in a decrease of physical activity [41]. Thus, a consequence of quarantine is limited physical activity that in turn results in an increased risk of developing obesity. On the contrary, previous studies reported that males are more active than females in leisure-time [42, 43]. Indeed Martin- Gonzalez et al. performed a study investigating the prevalence of physical activity during leisure time in adults from the 15 member states of the European Union and the relationship with socio demographic variables finding that a higher percentage of males practiced leisure-time physical activity [42]. Similar results were found by Steptoe et al. that carried out a survey in university students from 13 European countries (Belgium, England, France, Germany, Greece, Hungary, Iceland, Ireland, Italy, The Netherlands, Poland, Portugal, and
Spain) in 1990 and repeated in 2000 highlighting that the prevalence of leisure-time physical activity was higher in males [43]. Another aspect to be considered regards the diet that is known to affect both body weight and sleep quality $[4,44]$.

Evidence demonstrated that a higher energy intake notably from fat [45] and snacks [46], has been frequently reported in poor sleepers than in normal sleepers. NHANES data reported that poor sleepers compared to normal sleepers (7-8 h of sleep/night) had a lower consumption of protein, fat, carbohydrate, and fiber [47]. Clinical intervention studies have corroborated these evidences reporting that during sleep restriction fat was also highlighted as a macronutrient of choice in subjects with a normal habitual sleep [48, 49]. Although studies reported that there is a relationship between sleep quality and diet these epidemiologic evidence cannot address causality or the direction of the relation among these variables. In fact, it is unknown whether it is dietary intake that affects or sleep quality, or viceversa. Relationship between dietary patterns and sleep quality were recently showed in a cross-sectional study [50]. In this study, a high intake of fresh food like vegetables and fish, were associated with good sleep quality, whereas a high consumption of packaged and processed foods such as confectionary were associated with poor sleep quality, evaluated by a high global Pittsburgh Sleep Quality Index score [50]. Also a poor sleep quality was evident in subjects who consumed sugar-sweetened beverages or energy drinks [50]. In addition, other epidemiologic studies have found the relationship between diet and sleep quality [51-53], highlighting that both low and high intake of protein $(<16 \%$ and $>19 \%$ of energy from protein, respectively) were associated with poor sleep quality characterized by difficulty in maintaining sleep. Some foods, especially fresh ones, including fish, fruit, vegetables, and milk products have been identified as sleepinducers; however, longer-term effects of dietary intake on sleep quality have not been examined in randomized controlled studies $[4,44]$.

Even if not evaluated in this study, we hypothesize that a change in eating habits due to increased hunger and decreased satiety could contribute to weight gain observed in our studied population. Another important aspect to consider regarding diet is that during quarantine/lockdown, the individuals could have spent more time than usually happens in the kitchen for cook, with a consequent increase in the intake of carbohydrate, mostly pizza, homemade desserts and bread. In fact, as reported in the paragraph above, there is a bidirectional relationship between diet-obesity and sleep disturbance. Finally the house confinement imposed by quarantine could be associated to the decreased intake of fresh food, 
as fruit, vegetables and fish, all food rich in vitamins (including vitamin $\mathrm{C}$, beta-carotene, and vitamin $\mathrm{D}$ ), minerals (including selenium and zinc) and omega 3 fatty acids with anti-inflammatory and antioxidants activities. The low consumption of these micronutrients is associated with both obesity and sleep disturbance [54-56]; in particular, vitamin D plays a key role in the relationship between obesity and sleep disturbances [57-60].

\section{Working modalities}

Another interesting finding of our study is that smart working was associated to a greater deterioration of sleep quality that was more pronounced in males than females. This could be due to smart-device overuse and it is in agreement with a previous study carried out in 494 participants, from the three major cities in the United Arab Emirates finding that $81 \%$ of poor sleepers were heavy users of smart-devices thus concluding that poor sleep is strongly correlated with smart-device overuse [61]. In particular, poor sleepers have been reported to be five times more likely to be overuses [61]. Further, subjects in quarantine could be lead to check the news on phone, to join a virtual meeting with family or friends, to watch $\mathrm{TV}$, or to stay at computer later in the evening thus resulting in a huge increase in screen time. Excess screen time, especially later in the evening, can have a detrimental impact on sleep. Not only it can stimulate the brain in ways that makes it hard to wind down, but the blue light from screens can suppress the natural production of melatonin, a hormone that is known to be the main key player of sleep $[62,63]$.

\section{Limits and strengths}

We are aware that there are some limitations in the current study. First, the main limitation of this study is represented by a self-reported weight after quarantine. However, other studies have carried out the same evaluation modality [31]. Second, the sample size was relatively small. Nevertheless, we have calculated the sample size using $95 \%$ power. The number of cases required was 40 , while we used 121 individuals i.e. more than double those required. Third, although it is well known that dietary intake are important determinants of both weight gain and sleep disturbance, we did not include in this study the diet analysis.

However, the strengths of this study are several. In particular, this study provide unique information regarding a particular social condition represented by quarantine during a pandemic. Nevertheless, a major strength of this study is the homogeneity of our sample population that further strengthens the power of the study. In particular we have adopted stringent exclusion criteria including clinical conditions which could interfere with sleep quality like neurological disorders, chronic metabolic and cardiovascular diseases, and smoking subjects, known factors that can affect both sleep quality and weight gain making it possible to compare the variables independently across subjects. In addition, all study individuals lived in the same geographical area, Naples metropolitan area (latitude $40^{\circ} 49^{\prime} \mathrm{N}$; elevation $17 \mathrm{~m}$ ), likely with the similar nutrient availability and food consumption patterns, which allowed us to increase the homogeneity of the study sample. Furthermore, we included a variety of potential covariates, such gender and smart working, to minimize the effect of confounding factors on the role of quarantine/lockdown on sleep quality. An additional strength is the Pittsburg Sleep Quality Index questionnaire that was by phone administered and not self-reported in order to minimize any bias related to the filling of the questionnaire. To avoid inter-operator variability, only four expert nutritionists administered and calculated the Pittsburg Sleep Quality Index questionnaire and the telephone interview at the baseline and at the follow up.

\section{Conclusions}

To the best of our knowledge, this study was the first to investigate the acute impact of quarantine/lockdown due to the COVID-19 pandemic on sleep quality modification, after 40 days of quarantine/lockdown. In summary, our study demonstrated that quarantine was associated to a significant increase in BMI and a decrease in sleep quality. In particular, there was a worsening of sleep onset latency, sleep efficiency, sleep disturbances and daytime dysfunction. The worsening of sleep quality was higher in subjects doing smart working and this finding was more pronounced in males. Therefore, during quarantine it could be advisable to adopt lifestyle strategies in order to counteract quarantine-related sleep disturbances such as consuming food containing or promoting the synthesis of serotonin and melatonin at dinner such as roots, leaves, fruits, and seeds such as almonds, bananas, cherries, and oats and increasing physical activity.

\section{Abbreviations \\ SARS-CoV-2: Severe acute respiratory syndrome coronavirus 2; OSA: Obstruc- tive sleep apnea; SQ: Sleep quality; IL: Interleukin; TNF: Tumor necrosis factor; SD: Standard deviations; PSQI: Pittsburgh sleep quality index; BMI: Body mass index}

\section{Acknowledgements}

We are thankful to Panta Rei Impresa Sociale srl (https://www.panta-rei.eu/ pantarei/) and Pasquale Antonio Riccio, for their scientific support.

\section{Authors' contributions}

Substantial contributions to the conception or design of the work: LB and GM; the acquisition, analysis, or interpretation of data for the work: GP, LF, RDM, DL; Drafting the work or revising it critically for important intellectual content: LB, SS, AC and GM; Final approval of the version to be published: GM; Agreement 
to be accountable for all aspects of the work in ensuring that questions related to the accuracy or integrity of any part of the work are appropriately investigated and resolved: $L B, G P, L F, R D M, D L, S S, A C$ and $G M$. All authors read and approved the final manuscript.

\section{Funding}

This research received no external funding.

\section{Availability of data and materials}

All data generated or analyzed during this study are included in this published article.

\section{Ethics approval and consent to participate}

The study was conducted in full agreement with the national and international regulations and the Declaration of Helsinki (2000). All participants were fully informed about the study requirements and were required to accept the data sharing and privacy policy before participating in the study.

\section{Consent for publication}

Not applicable.

\section{Competing Interests}

None of the Authors have conflicts of interest to declare.

\begin{abstract}
Author details
${ }^{1}$ Dipartimento di Medicina Clinica e Chirurgia, Unit of Endocrinology, Federico II University Medical School of Naples, Via Sergio Pansini 5, 80131 Naples, Italy. ${ }^{2}$ Centro Italiano per la cura e il Benessere del Paziente con Obesità (C.I.B.O), Department of Clinical Medicine and Surgery, Endocrinology Unit, University Medical School of Naples, Via Sergio Pansini 5, 80131 Naples, Italy. ${ }^{3}$ Cattedra Unesco "Educazione alla salute e allo sviluppo sostenibile", University Federico II, Naples, Italy.
\end{abstract}

Received: 1 June 2020 Accepted: 28 July 2020

Published online: 18 August 2020

\section{References}

1. Velavan TP, Meyer CG. The COVID-19 epidemic. Tropical Med Int Health. 2020;25(3):278-80. https://doi.org/10.1111/tmi.13383.

2. Gazzetta Ufficiale della Repubblica Italiana. No Title. 9 March. 2020 (cited 2020 May 4). p. 16. https://www.gazzettaufficiale.it/eli/ id/2020/03/09/20A01558/sg.

3. St-Onge MP. Sleep-obesity relation: underlying mechanisms and consequences for treatment. Obesity Rev. 2017;18(Suppl 1):34-9. https://doi. org/10.1111/obr.12499.

4. Binks H, Vincent GE, Gupta C, Irwin C, Khalesi S. Effects of diet on sleep: a narrative review. Nutrients. 2020;12(4):936. https://doi.org/10.3390/nu120 40936.

5. St-Onge MP, Roberts A, Shechter A, Choudhury AR. Fiber and saturated fat are associated with sleep arousals and slow wave sleep. J Clin Sleep Med. 2016;12(1):19-24. https://doi.org/10.5664/jcsm.5384.

6. Touitou Y, Reinberg A, Touitou D. Association between light at night, melatonin secretion, sleep deprivation, and the internal clock: health impacts and mechanisms of circadian disruption. Life Sci. 2017;173:94-106. https ://doi.org/10.1016/j.lfs.2017.02.008

7. Meng X, Li Y, Li S, Zhou Y, Gan RY, Xu DP, et al. Dietary sources and bioactivities of melatonin. Nutrients. 2017;9(4):367. https://doi.org/10.3390/ nu9040367.

8. Yllmaz C, Gökmen V. Neuroactive compounds in foods: Occurrence, mechanism and potential health effects. Food Res Int. 2020;128:108744. https://doi.org/10.1016/j.foodres.2019.108744.

9. Wu Z, Kong F, Wang Y, Sun R, Chen L. The impact of greenspace on thermal comfort in a residential quarter of Beijing, China. Int J Environ Res Public Health. 2016;13(12):1217. https://doi.org/10.3390/ijerph13121217.

10. van Strien T. Causes of emotional eating and matched treatment of obesity. Curr Diabetes Rep. 2018;18(6):35. https://doi.org/10.1007/s1189 2-018-1000-x.

11. Evers $C$, Dingemans A, Junghans AF, Boevé A. Feeling bad or feeling good, does emotion affect your consumption of food? A meta-analysis of the experimental evidence. Neurosci Biobehav Rev. 2018;92:195-208. https://doi.org/10.1016/j.neubiorev.2018.05.028.

12. Muscogiuri G, Barrea L, Annunziata G, Di Somma C, Laudisio D, Colao A, et al. Obesity and sleep disturbance: the chicken or the egg? Crit Rev Food Sci Nutr. 2019;59(13):2158-65. https://doi.org/10.1080/10408 398.2018.1506979.

13. Pugliese G, Barrea L, Laudisio D, Salzano C, Aprano S, Colao A, et al. Sleep apnea, obesity, and disturbed glucose homeostasis: epidemiologic evidence, biologic insights, and therapeutic strategies. Curr Obesity Rep. 2020;9(1):30-8. https://doi.org/10.1007/s13679-020-00369-y.

14. Hamilton GS, Joosten SA. Obstructive sleep apnoea and obesity. Australian Family Physician. 2017;46(7):460-3.

15. Labarca G, Gower J, Lamperti L, Dreyse J, Jorquera J. Chronic intermittent hypoxia in obstructive sleep apnea: a narrative review from pathophysiological pathways to a precision clinical approach. Sleep Breathing. 2019;24(2):751-60. https://doi.org/10.1007/s11325-019-01967-4.

16. Resta O, Foschino Barbaro MP, Bonfitto P, Giliberti T, Depalo A, Pannacciulli $\mathrm{N}$, et al. Low sleep quality and daytime sleepiness in obese patients without obstructive sleep apnoea syndrome. J Internal Med. 2003;253(5):53643. https://doi.org/10.1046/j.1365-2796.2003.01133.x.

17. Eslick GD, Talley NJ. Gastrointestinal symptoms negatively impact on sleep quality among obese individuals: a population-based study. Sleep Breathing. 2016;20(1):363-7. https://doi.org/10.1007/s11325-015-1282-z.

18. Sperry SD, Scully ID, Gramzow RH, Jorgensen RS. Sleep duration and waist circumference in adults: a meta-analysis. Sleep. 2015;38(8):1269-76. https ://doi.org/10.5665/sleep.4906.

19. Chait A, den Hartigh L. Adipose tissue distribution, inflammation and its metabolic consequences, including diabetes and cardiovascular disease. Front Cardiovasc Med. 2020;7:22. https://doi.org/10.3389/ fcrm.2020.00022.

20. Landecho MF, Tuero C, Valentí V, Bilbao I, de la Hiquera M, Frühbeck G. Relevance of leptin and other adipokines in obesity-associated cardiovascular risk. Nutrients. 2019;11(11):2664. https://doi.org/10.3390/nu111 12664.

21. Perrini S, Cignarelli A, Quaranta VN, Falcone VA, Kounaki S, Porro S, et al. Correction of intermittent hypoxia reduces inflammation in obese subjects with obstructive sleep apnea. JCI Insight. 2017;2(17):e94379. https:// doi.org/10.1172/jci.insight.94379.

22. Haspel JA, Anafi R, Brown MK, Cermakian N, Depner C, Desplats P, et al. Perfect timing: circadian rhythms, sleep, and immunity —an Nih workshop summary. JCl Insight. 2020;5(1):e131487. https://doi.org/10.1172/jci. insight.131487.

23. Moynihan $A B$, van Tilburg WAP, Igou ER, Wisman A, Donnelly AE, Mulcaire JB. Eaten up by boredom: Consuming food to escape awareness of the bored self. Front Psychol. 2015;6:369. https://doi.org/10.3389/fpsyg 2015.00369.

24. Barrea L, Fabbrocini G, Annunziata G, Muscogiuri G, Donnarumma M, Marasca C, et al. Role of nutrition and adherence to the mediterranean diet in the multidisciplinary approach of hidradenitis suppurativa: evaluation of nutritional status and its association with severity of disease. Nutrients. 2019:11(1):57. https://doi.org/10.3390/nu11010057.

25. Barrea L, Tarantino G, Di Somma C, Muscogiuri G, Macchia PE, Falco A, et al. Adherence to the mediterranean diet and circulating levels of sirtuin 4 in obese patients: a novel association. Oxid Med Cell Longev. 2017:2017:6101254. https://doi.org/10.1155/2017/6101254

26. Barrea L, Muscogiuri G, Di Somma C, Annunziata G, Megna M, Falco A, et al. Coffee consumption, metabolic syndrome and clinical severity of psoriasis: good or bad stuff? Arch Toxicol. 2018;92(5):1831-45. https://doi. org/10.1007/s00204-018-2193-0.

27. Barrea L, Muscogiuri G, Di Somma C, Tramontano G, De Luca V, Illario M, et al. Association between Mediterranean diet and hand grip strength in older adult women. Clin Nutr. 2019;38(2):721-9. https://doi.org/10.1016/j. clnu.2018.03.012.

28. Savanelli MC, Scarano E, Muscogiuri G, Barrea L, Vuolo L, Rubino M, et al. Cardiovascular risk in adult hypopituitaric patients with growth hormone deficiency: is there a role for vitamin D? Endocrine. 2016;52(1):111-9. https://doi.org/10.1007/s12020-015-0779-3.

29. Savastano S, Di Somma C, Colao A, Barrea L, Orio F, Finelli C, et al. Preliminary data on the relationship between circulating levels of Sirtuin 4, anthropometric and metabolic parameters in obese subjects according 
to growth hormone/insulin-like growth factor-1 status. Growth Horm IGF Res. 2015;25(1):28-33. https://doi.org/10.1016/j.ghir.2014.10.006.

30. WHO. World Health Organization. (cited 2020 May 4). http://www.euro. who.int/en/health-topics/disease-prevention/nutrition/a-healthy-lifes tyle/body-mass-index-bmi.

31. Dekkers JC, Van Wier MF, Hendriksen IJM, Twisk JWR, Van Mechelen W. Accuracy of self-reported body weight, height and waist circumference in a Dutch overweight working population. BMC Med Res Methodol. 2008:8:69. https://doi.org/10.1186/1471-2288-8-69.

32. Buysse DJ, Reynolds CF, Monk TH, Berman SR, Kupfer DJ. The Pittsburgh sleep quality index: a new instrument for psychiatric practice and research. Psychiatry Res. 1989;28(2):193-213. https://doi. org/10.1016/0165-1781(89)90047-4.

33. Barrea L, Annunziata G, Muscogiuri G, Laudisio D, Di Somma C, Maisto $M$, et al. Trimethylamine $\mathrm{N}$-oxide, Mediterranean diet, and nutrition in healthy, normal-weight adults: also a matter of sex? Nutrition. 2019;62:717. https://doi.org/10.1016/j.nut.2018.11.015.

34. Barrea L, Macchia PE, Di Somma C, Napolitano M, Balato A, Falco A, et al. Bioelectrical phase angle and psoriasis: a novel association with psoriasis severity, quality of life and metabolic syndrome. J Transl Med. 2016;14(1):130. https://doi.org/10.1186/s12967-016-0889-6.

35. Chrousos GP. The role of stress and the hypothalamic-pituitary-adrenal axis in the pathogenesis of the metabolic syndrome: neuro-endocrine and target tissue-related causes. Int J Obesity. 2000;24(Suppl 2):S50-5. https://doi.org/10.1038/sj.ijo.0801278.

36. Gold PW, Goodwin FK, Chrousos GP. Clinical and Biochemical manifestations of depression. Relation to the neurobiology of stress (Second of two parts). N Engl J Med. 1988;319(7):413-20. https://doi.org/10.1056/nejm1 98808183190706

37. Dixon $A E$, Peters $U$. The effect of obesity on lung function. Expert Rev Resp Med. 2018;12(9):755-67. https://doi.org/10.1080/17476 348.2018.1506331.

38. Gamaldo CE, Shaikh AK, McArthur JC. The sleep-immunity relationship. Neurol Clin. 2012;30(4):1313-43. https://doi.org/10.1016/j.ncl.2012.08.007.

39. Irwin MR. Sleep and inflammation: partners in sickness and in health. Nat Rev Immunol. 2019;19(11):702-15. https://doi.org/10.1038/s4157 7-019-0190-z.

40. Covelli V, Massari F, Fallacara C, Munno I, Jirillo E, Savastano S, et al. Interleukin-ibeta and beta-endorphin orcadian rhythms are inversely related in normal and stress-altered sleep. Int J Neurosci. 1992;63(3-4):299-305. https://doi.org/10.3109/00207459208987204.

41. Mattioli AV, Sciomer S, Cocchi C, Maffei S, Gallina S. Quarantine during COVID-19 outbreak: changes in diet and physical activity increase the risk of cardiovascular disease. Nutr Metab Cardiovasc Dis. 2020;509394753(20):30213-1. https://doi.org/10.1016/j.numecd.2020.05.020.

42. Martinez-Gonzalez MA, Varo JJ, Santos JL, De Irala J, Gibney M, Kearney J, et al. Prevalence of physical activity during leisure time in the European Union. Med Sci Sports Exerc. 2001;33(7):1142-6. https://doi. org/10.1097/00005768-200107000-00011.

43. Steptoe A, Wardle J, Cui W, Bellisle F, Zotti AM, Baranyai R, et al. Trends in smoking, diet, physical exercise, and attitudes toward health in European university students from 13 countries, 1990-2000. Prev Med. 2002;35(2):97-104. https://doi.org/10.1006/pmed.2002.1048.

44. St-Onge M-P, Mikic A, Pietrolungo CE. Effects of diet on sleep quality. Adv Nutr. 2016;7(5):938-49. https://doi.org/10.3945/an.116.012336.

45. Weiss A, Xu F, Storfer-Isser A, Thomas A, levers-Landis CE, Redline S. The association of sleep duration with adolescents' fat and carbohydrate consumption. Sleep. 2010;33(9):1201-9. https://doi.org/10.1093/sleep /33.9.1201.

46. Grandner MA, Kripke DF, Naidoo N, Langer RD. Relationships among dietary nutrients and subjective sleep, objective sleep, and napping in women. Sleep Med. 2010;11(2):180-4. https://doi.org/10.1016/j.sleep 2009.07.014.

47. Grandner MA, Jackson N, Gerstner JR, Knutson KL. Dietary nutrients associated with short and long sleep duration. Data from a nationally representative sample. Appetite. 2013;64:71-80. https://doi.org/10.1016/j. appet.2013.01.004.

48. St-Onge MP, Roberts AL, Chen J, Kelleman M, O'Keeffe M, RoyChoudhury $A$, et al. Short sleep duration increases energy intakes but does not change energy expenditure in normal-weight individuals. Am J Clin Nutr. 2011;94(2):410-6. https://doi.org/10.3945/ajcn.111.013904.

49. Schmid SM, Hallschmid M, Jauch-Chara K, Wilms B, Benedict C, Lehnert $\mathrm{H}$, et al. Short-term sleep loss decreases physical activity under free-living conditions but does not increase food intake under time-deprived laboratory conditions in healthy men. Am J Clin Nutr. 2009;90(6):1476-82. https://doi.org/10.3945/ajcn.2009.27984.

50. Katagiri R, Asakura K, Kobayashi S, Suga H, Sasaki S. Low intake of vegetables, high intake of confectionary, and unhealthy eating habits are associated with poor sleep quality among middle-aged female Japanese workers. J Occupational Health. 2014;56(5):359-68. https://doi. org/10.1539/joh.14-0051-oa.

51. Tanaka E, Yatsuya H, Uemura M, Murata C, Otsuka R, Toyoshima H, et al. Associations of protein, fat, and carbohydrate intakes with insomnia symptoms among middle-aged Japanese workers. J Epidemiol. 2013;23(2):132-8. https://doi.org/10.2188/jea.je20120101.

52. Tan X, Alén M, Cheng SM, Mikkola TM, Tenhunen J, Lyytikäinen A, et al. Associations of disordered sleep with body fat distribution, physical activity and diet among overweight middle-aged men. J Sleep Res. 2015;24(4):414-24. https://doi.org/10.1111/jsr.12283.

53. Jaussent I, Dauvilliers Y, Ancelin ML, Dartigues JF, Tavernier B, Touchon $J$, et al. Insomnia symptoms in older adults: associated factors and gender differences. Am J Geriatr Psychiatry. 2011;19(1):88-97. https://doi. org/10.1097/JGP.0b013e3181e049b6.

54. Ghanemi A, Yoshioka M, St-Amand J. Broken energy homeostasis and obesity pathogenesis: the surrounding concepts. J Clin Med. 2018:7(11):453. https://doi.org/10.3390/jcm7110453.

55. Dobrosielski DA, Papandreou C, Patil SP, Salas-Salvadó J. Diet and exercise in the management of obstructive sleep apnoea and cardiovascular disease risk. Eur Resp Rev. 2017;26(144):160110. https://doi. org/10.1183/16000617.0110-2016

56. Pot GK. Sleep and dietary habits in the urban environment: the role of chrono-nutrition. Proc Nutr Soc. 2018;77(3):189-98. https://doi. org/10.1017/S0029665117003974.

57. Barrea L, Savastano S, DSomma C, Savanelli MC, Nappi FF, Albanese L, et al. Low serum vitamin D-status, air pollution and obesity: a dangerous liaison. Rev Endocr Metab Disorders. 2016;18(2):207-14. https://doi. org/10.1007/s11154-016-9388-6.

58. Muscogiuri G, Barrea L, Scannapieco M, Di Somma C, Scacchi M, Aimarett $\mathrm{G}$, et al. The lullaby of the sun: the role of vitamin $\mathrm{D}$ in sleep disturbance. Sleep Med. 2019;54:262-5. https://doi.org/10.1016/j.sleep.2018.10.033.

59. Barrea L, Muscogiuri G, Annunziata G, Laudisio D, Tenore GC, Colao A, et al. A new light on vitamin $d$ in obesity: a novel association with trimethylamine-n-oxide (tmao). Nutrients. 2019;1 (6):1310. https://doi. org/10.3390/nu11061310.

60. Muscogiuri G, Barrea L, Di Somma C, Laudisio D, Salzano C, Pugliese G, et al. Sex differences of vitamin D status across BMI classes: an observational prospective cohort study. Nutrients. 2019;1 1(12):3034. https://doi. org/10.3390/nu11123034

61. Abedalqader F, Al-Deen Alhuarrat M, Ibrahim G, Taha F, Al Tamimi A, Shukur M, et al. The correlation between smart device usage \& sleep quality among UAE residents. Sleep Med. 2019;63:18-23. https://doi. org/10.1016/j.sleep.2019.04.017.

62. Sroykham W, Wongsawat Y. Effects of LED-backlit computer screen and emotional selfregulation on human melatonin production. Proceedings of the Annual International Conference of the IEEE Engineering in Medicine and Biology Society, EMBS. 2013;2013:1704-7. doi: 10.1109/ EMBC.2013.6609847.

63. Cajochen C, Frey S, Anders D, Späti J, Bues M, Pross A, et al. Evening exposure to a light-emitting diodes (LED)-backlit computer screen affects circadian physiology and cognitive performance. J Appl Physiol. 2011;110(5):1432-8. https://doi.org/10.1152/japplphysiol.00165.2011.

\section{Publisher's Note}

Springer Nature remains neutral with regard to jurisdictional claims in published maps and institutional affiliations. 